This item was submitted to Loughborough's Research Repository by the author.

Items in Figshare are protected by copyright, with all rights reserved, unless otherwise indicated.

\title{
Solubility and thermodynamics of D-glucosamine 2-sulfate sodium salt in water and binary solvent mixtures with methanol, ethanol and n-propanol
}

PLEASE CITE THE PUBLISHED VERSION

https://doi.org/10.1016/j.molliq.2019.112218

\section{PUBLISHER}

Elsevier

VERSION

AM (Accepted Manuscript)

\section{PUBLISHER STATEMENT}

This paper was accepted for publication in the journal Journal of Molecular Liquids and the definitive published version is available at https://doi.org/10.1016/j.molliq.2019.112218

LICENCE

CC BY-NC-ND 4.0

\section{REPOSITORY RECORD}

Wang, Lijie, Huaiyu Yang, Zehao Si, YiZhen Yan, Xiangyang Zhang, and Xinggui Zhou. 2019. "Solubility and Thermodynamics of D-glucosamine 2-sulfate Sodium Salt in Water and Binary Solvent Mixtures with Methanol, Ethanol and N-propanol". Loughborough University. https://hdl.handle.net/2134/14046986.v1. 


\title{
Thermodynamics of D-glucosamine 2-sulfate sodium salt in water and (methanol, ethanol, n-propanol) binary solvent mixtures
}

\author{
Lijie Wang ${ }^{1}$, Huaiyu Yang ${ }^{2}$, Zehao Si ${ }^{1}$, Xiangyang Zhang ${ }^{1}{ }^{*}$, Xinggui Zhou ${ }^{1}$ \\ ${ }^{1}$ State Key Laboratory of Chemical Engineering, East China University of Science and \\ Technology, Shanghai, 200237, China \\ ${ }^{2}$ Department of Chemical Engineering, Loughborough University, Loughborough, LE11 3TU, UK
}

\section{Abstract:}

Solubility of D-glucosamine 2-sulfate sodium salt in water and binary aqueous mixtures with methanol, ethanol or n-propanol were firstly reported from $288.15 \mathrm{~K}$ to $318.15 \mathrm{~K}$ under $0.1 \mathrm{MPa}$. The results showed that the solubility of GS in water is about three orders of magnitude higher than its solubility in alcohols, and the solubility increases with increasing temperature and the composition of the alcohols. Thermodynamic properties of D-glucosamine 2-sulfate sodium salt, such as melting temperature, and decomposition temperature were determined by DSC and TGA. The solubility in various pure and binary solvents was correlated and compared by the modified Apelblat equation, Jouyban-Acree model, Wilson model, and NRTL model. Mixing thermodynamic properties, such as the mixing Gibbs energy, mixing enthalpy, and the mixing entropy of D-glucosamine 2-sulfate sodium salt in these solvents were estimated and analysed.

\footnotetext{
${ }^{*}$ Corresponding author. Tel: +86-21-64253509. Fax: +86-21-64253528.

E-mail address: zxydcom@ecust.edu.cn (Xiangyang Zhang)
} 
Keywords: D-glucosamine 2-sulfate sodium salt; Solubility; Thermodynamics;

Binary solvent mixtures; Water 


\section{INTRODUCTION}

D-glucosamine 2-sulfate sodium salt (GS), a sulfate derivative of glucosamine, is derived from chitin and has anti-inflammatory effects [1,2]. In vitro, GS can reduce expression of inflammatory markers, including IL-1 $\beta$, COX-2, IL-6, and TNF- $\alpha$ in IL-1 $\beta$-activated human chondrosarcoma SW1353 cells at a minimum effective concentration of $1 \mu \mathrm{M}$ [3]. It limits expression of matrix metalloproteinase3 (MMP-3) and a disintegrin and metalloproteinase with thrombospondin motifs 5 (ADAMTS-5), both markers of matrix degradation. Treating human primary chondrocytes with GlcN-2S stimulates proteoglycan production at a dose of 10 $\mu \mathrm{g} / \mathrm{mL}$ and adhesion to fibronectin at a concentration of $50 \mu \mathrm{M}$ [4]. Besides, GS can stimulate chondrocytes to produce more glycoproteins with a normal multimeric structure and inhibit certain enzymes that impair articular cartilage such as collagenase and phospholipase A2 [5]. GS is widely used for the prevention and treatment of various types of osteoarthritis, such as the knee, hip, spine, shoulder, wrist and osteoarthritis [6,7].

Cooling crystallization with water is commonly used for purification of GS in industry [8], and water is the most common used and most safe solvent in pharmaceutical crystallization. However, due to high solubility of GS in the water, the aqueous solution at the end of the cooing crystallization still dissolves much GS, leading to a relatively low yield. Antisolvent crystallization $[9,10]$, by mixing second solvent with very low solubility into water, can be used to improve the yield. However, there is no relavent solubility reported for design the antisolvent 
crystallization process. The mixed solvents studies have significant applications in multiple fields, such as nanomaterials preparation, nanosheet fabrication, drug formulation, colloids preparation for corrosion inhibitor and inorganic salts $[11,12,13]$. It's very important to determine the solubility $[14,15]$ and polymorphism for rapid screening of favorable mixed solvents and further optimizing the crystallization process[16,17]. Furthermore, the screening of solubility and polymorph is also essential to provide guidance to dissolution process, formulation and tableting developments [18].

In this work, three commonly used and safe (low toxic) antisolvents, methanol, ethanol, n-propanol, were selected $[19,20]$. Solubility of GS in water and mixtures with methanol, ethanol, n-propanol at six volume fractions $(0 \%, 25 \%, 50 \%, 75 \%$, $90 \%$, and $100 \%$ ) were determined in the range of $288.15 \mathrm{~K}$ to $318.15 \mathrm{~K}$ under 0.1 MPa. The Apelblat equation model, Jouyban-Acree model, Wilson model and NRTL model were fully applied to the fitting of solubility respectively. The characterization methods of the solid-state characterization like FTIR and PXRD were used for distinguishing polymorphisms of GS. Thermodynamic properties, including melting temperature $T_{\mathrm{m}}$ and decomposition temperature, were determined by the DSC and TGA. The correlations between solubility, calculated activity coefficients, and mixing enthalpy, entropy and free energy of GS in different binary solvents were discussed.

\section{THEORETICAL MODELS}




\subsection{Modified Apelblat Equation}

The modified Apelblat equation[21] is given by

$$
\ln x_{l}=\mathrm{A}+\frac{\mathrm{B}}{\mathrm{T}}+\mathrm{C} \ln \mathrm{T}
$$

where $x_{1}$ is mole fraction solubility of the solute at temperature $T$. A, B, and C are the empirical constants.

\subsection{Jouyban-Acree model}

Jouyban-Acree model can be used to correlate molar solubility with different compositions of binary solvents [22]:

$$
\ln \mathrm{x}_{1}=\mathrm{x}_{2} \ln \mathrm{X}_{2}+\mathrm{x}_{3} \ln \mathrm{X}_{3}+\mathrm{x}_{2} \mathrm{x}_{3} \sum_{\mathrm{i}=0}^{\mathrm{N}} \frac{\mathrm{J}_{\mathrm{i}}\left(\mathrm{x}_{2}-\mathrm{x}_{3}\right)^{\mathrm{i}}}{\mathrm{T}}
$$

where $J_{i}$ is a constant, $T$ represents the absolute temperature, $x_{2}$ and $x_{3}$ are initial mole fraction composition of the organic solvent and the water in the binary solvent mixtures. For the binary system ( $N=2)$, Eq. (2) can be simplified as

$$
\mathrm{T} \ln \mathrm{x}_{1}=\mathrm{A}_{0}+\mathrm{A}_{1} \mathrm{~T}+\mathrm{A}_{2} \mathrm{Tx}_{2}+\mathrm{A}_{3} \mathrm{x}_{2}+\mathrm{A}_{4} \mathrm{x}_{2}^{2}+\mathrm{A}_{5} \mathrm{x}_{2}^{3}+\mathrm{A}_{6} \mathrm{x}_{2}^{4}
$$

where $A_{0}, A_{1}, A_{2}, A_{3}, A_{4}, A_{5}$, and $A_{6}$ are constants [23].

\subsection{Wilson model}

Wilson model is widely used to correlate and predict solid-liquid equilibrium properties for non-ideal solutions [24]:

$$
\begin{aligned}
& \ln \gamma_{1}=1-\ln \left(\mathrm{x}_{1}+\Lambda_{12} \mathrm{x}_{2}+\Lambda_{13} \mathrm{x}_{3}\right)-\frac{\mathrm{x}_{1}}{\mathrm{x}_{1}+\Lambda_{12} \mathrm{x}_{2}+\Lambda_{13} \mathrm{x}_{3}}-\frac{\Lambda_{21} \mathrm{x}_{2}}{\mathrm{x}_{2}+\Lambda_{21} \mathrm{x}_{1}+\Lambda_{23} \mathrm{x}_{3}} \\
& -\frac{\Lambda_{31} \mathrm{x}_{3}}{\mathrm{x}_{3}+\Lambda_{31} \mathrm{x}_{1}+\Lambda_{32} \mathrm{x}_{2}}
\end{aligned}
$$




$$
\begin{aligned}
& \ln \gamma_{2}=1-\ln \left(\mathrm{x}_{2}+\Lambda_{21} \mathrm{x}_{1}+\Lambda_{23} \mathrm{x}_{3}\right)-\frac{\Lambda_{12} \mathrm{x}_{1}}{\mathrm{x}_{1}+\Lambda_{12} \mathrm{x}_{2}+\Lambda_{13} \mathrm{x}_{3}}-\frac{\mathrm{x}_{2}}{\mathrm{x}_{2}+\Lambda_{21} \mathrm{x}_{1}+\Lambda_{23} \mathrm{x}_{3}} \\
& -\frac{\Lambda_{32} \mathrm{x}_{3}}{\mathrm{x}_{3}+\Lambda_{31} \mathrm{x}_{1}+\Lambda_{32} \mathrm{x}_{2}} \\
& \ln \gamma_{3}=1-\ln \left(\mathrm{x}_{3}+\Lambda_{32} \mathrm{x}_{2}+\Lambda_{31} \mathrm{x}_{1}\right)-\frac{\Lambda_{13} \mathrm{x}_{1}}{\mathrm{x}_{1}+\Lambda_{12} \mathrm{x}_{2}+\Lambda_{13} \mathrm{x}_{3}}-\frac{\Lambda_{23} \mathrm{x}_{2}}{\mathrm{x}_{2}+\Lambda_{21} \mathrm{x}_{1}+\Lambda_{23} \mathrm{x}_{3}} \\
& -\frac{\mathrm{x}_{3}}{\mathrm{x}_{3}+\Lambda_{32} \mathrm{x}_{2}+\Lambda_{31} \mathrm{x}_{1}} \\
& \Lambda_{\mathrm{ij}}=\frac{v_{\mathrm{j}}}{v_{\mathrm{i}}} \exp \left[-\left(\lambda_{\mathrm{ij}}-\lambda_{\mathrm{ii}}\right) / \mathrm{RT}\right]
\end{aligned}
$$

where $v_{1}, v_{2}$, and $v_{3}$ represent molar volume of solute and two solvents, respectively. $\Lambda_{\mathrm{ij}}-\lambda_{\mathrm{ii}}$ represents cross interaction energy parameters, which are assumed to be independent of the temperature and the composition.

\subsection{NRTL model}

NRTL model overcomes the limitation of Wilson model, which can not correlate partial miscible systems [25]

$$
\begin{aligned}
& \ln \gamma_{1}=\frac{\left(G_{21} x_{2}+G_{31} x_{3}\right)\left(\tau_{21} G_{21} x_{2}+\tau_{31} G_{31} x_{3}\right)}{\left(x_{1}+G_{21} x_{2}+G_{31} x_{3}\right)^{2}}+\frac{\tau_{12} G_{12} x_{2}^{2}+G_{12} G_{32} x_{2} x_{3}\left(\tau_{12}-\tau_{32}\right)}{\left(G_{12} x_{1}+x_{2}+G_{32} x_{3}\right)^{2}} \\
& +\frac{\tau_{13} G_{13} x_{3}^{2}+G_{13} G_{23} x_{2} x_{3}\left(\tau_{13}-\tau_{23}\right)}{\left(G_{13} x_{1}+G_{23} x_{2}+x_{3}\right)^{2}} \\
& \ln \gamma_{2}=\frac{\left(G_{32} x_{3}+G_{12} x_{1}\right)\left(\tau_{32} G_{32} x_{3}+\tau_{12} G_{12} x_{1}\right)}{\left(x_{2}+G_{32} x_{3}+G_{12} x_{1}\right)^{2}}+\frac{\tau_{23} G_{23} x_{3}^{2}+G_{23} G_{13} x_{1} x_{3}\left(\tau_{23}-\tau_{13}\right)}{\left(G_{23} x_{2}+x_{3}+G_{13} x_{1}\right)^{2}} \\
& +\frac{\tau_{21} G_{21} x_{1}^{2}+G_{21} G_{31} x_{1} x_{3}\left(\tau_{21}-\tau_{31}\right)}{\left(G_{21} x_{2}+G_{31} x_{3}+x_{1}\right)^{2}} \\
& \ln \gamma_{3}=\frac{\left(G_{13} x_{1}+G_{23} x_{2}\right)\left(\tau_{13} G_{13} x_{1}+\tau_{23} G_{23} x_{2}\right)}{\left(x_{3}+G_{13} x_{1}+G_{23} x_{2}\right)^{2}}+\frac{\tau_{21} G_{31} x_{1}^{2}+G_{31} G_{21} x_{1} x_{2}\left(\tau_{31}-\tau_{21}\right)}{\left(G_{31} x_{3}+x_{1}+G_{21} x_{2}\right)^{2}} \\
& +\frac{\tau_{32} G_{32} x_{2}^{2}+G_{32} G_{12} x_{1} x_{2}\left(\tau_{32}-\tau_{12}\right)}{\left(G_{32} x_{3}+G_{12} x_{1}+x_{2}\right)^{2}}
\end{aligned}
$$

With

$$
\tau_{i j}=\frac{g_{i j}-g_{j i}}{R T}=\frac{\Delta g_{i j}}{R T}
$$




$$
G_{i j}=\exp \left(-\alpha_{i j} \tau_{i j}\right)
$$

where $\Delta g_{\mathrm{ij}}$ and $\alpha_{\mathrm{ij}}$ represent the cross interaction energy parameters $(\mathrm{J} / \mathrm{mol})$ and the measure of the mixture's nonrandomness. The value of $\alpha_{i j}$ usually lies between 0.20 and $0.47[26]$.

\subsection{Mixing thermodynamic properties}

In non-ideal solution, the mixing properties such as the mixing Gibbs free energy $\left(\Delta_{\text {mix }} G\right)$, the mixing enthalpy $\left(\Delta_{\text {mix }} H\right)$, and the mixing entropy $\left(\Delta_{\text {mix }} S\right)$ can be estimated by the following equations [27]:

$$
\begin{gathered}
\Delta_{\text {mix }} \mathrm{G}=\Delta \mathrm{G}^{\mathrm{E}}+\Delta_{\mathrm{m}} \mathrm{G}^{\mathrm{id}} \\
\Delta_{\text {mix }} \mathrm{H}=\Delta \mathrm{H}^{\mathrm{E}}+\Delta_{\mathrm{m}} \mathrm{H}^{\text {id }} \\
\Delta_{\text {mix }} \mathrm{S}=\Delta \mathrm{S}^{\mathrm{E}}+\Delta_{\mathrm{m}} \mathrm{S}^{\text {id }}
\end{gathered}
$$

where $\Delta G^{\mathrm{E}}, \Delta H^{\mathrm{E}}$, and $\Delta S^{\mathrm{E}}$ are excess properties, $\Delta G^{\mathrm{id}}, \Delta H^{\text {id }}$, and $\Delta S^{\text {id }}$ represent mixing properties of an ideal system, respectively. The latter properties can be calculated by the following equations:

$$
\begin{aligned}
& \Delta_{\mathrm{m}} \mathrm{G}^{\mathrm{id}}=\mathrm{RT} \sum_{\mathrm{i}=}^{\mathrm{n}} \mathrm{x}_{\mathrm{i}} \ln \mathrm{x}_{\mathrm{i}} \\
& \Delta_{\mathrm{m}} \mathrm{S}^{\mathrm{id}}=-\mathrm{R} \sum_{\mathrm{i}=}^{\mathrm{n}} \mathrm{x}_{\mathrm{i}} \ln \mathrm{x}_{\mathrm{i}} \\
& \Delta_{\mathrm{m}} \mathrm{H}^{\mathrm{id}}=0
\end{aligned}
$$

The excess properties can be expressed as follows :

$$
\begin{aligned}
& \Delta \mathrm{G}^{\mathrm{E}}=\mathrm{RT} \sum_{\mathrm{i}=}^{\mathrm{n}} \mathrm{x}_{\mathrm{i}} \ln \gamma_{\mathrm{i}} \\
& \Delta \mathrm{S}^{\mathrm{E}}=-\mathrm{R} \sum_{\mathrm{i}=}^{\mathrm{n}} \mathrm{x}_{\mathrm{i}} \ln \gamma_{\mathrm{i}}-\mathrm{RT} \sum_{\mathrm{i}=}^{\mathrm{n}} \mathrm{x}_{\mathrm{i}}\left(\frac{\partial \ln \gamma_{\mathrm{i}}}{\partial \mathrm{T}}\right)_{P, X}
\end{aligned}
$$




$$
\Delta \mathrm{H}^{\mathrm{E}}=-\mathrm{RT}^{2} \sum_{\mathrm{i}=\mathrm{x}}^{\mathrm{n}} \mathrm{x}_{\mathrm{i}}\left(\frac{\partial \ln \gamma_{\mathrm{i}}}{\partial \mathrm{T}}\right)_{\mathrm{P}, \mathrm{X}}
$$

Here, the activity coefficient can be calculated by NRTL model.

\section{Experimental}

D-glucosamine 2-sulfate sodium salt $\left(\mathrm{C}_{6} \mathrm{H}_{12} \mathrm{NO}_{8} \mathrm{~S} \cdot \mathrm{Na}\right.$, CAS Number 3889905-7), was supplied by Hisun Co., Ltd., China, with purity > 99.5 wt. \% determined by HPLC (Shimadzu LC-20A). Fig. 1 shows molecular structure of GS. Organic solvents methanol, ethanol, and n-propanol (>99.5 wt.\%) were purchased from Titan Technology Co., Ltd and used without further purification. Distilled water was filtered through a $0.2 \mu \mathrm{m}$ filter before using as shown in Table 1.

Solubility of GS in different binary solvent mixtures was measured by gravimetric method [28]. Excess amount of GS were added into a sealed conical flask with solvents inside. The solution in conical flask was vibrated at a speed of $150 \mathrm{rpm}$ in a Water-bathing Constant Temperature Vibrator (SW22, Julabo Laboretechnik Gmbh, Germany) at constant temperature. Equilibrium was reached by more than $24 \mathrm{~h}$ vibration, with temperature uncertainty of $\pm 0.01 \mathrm{~K}$. Then, the solution was kept still for $12 \mathrm{~h}$ to ensure complete sedimentation of fine crystals. Later, samples were extracted from upper clear solution by a $5 \mathrm{~mL}$ suction pipet equipped with a $0.22 \mu \mathrm{m}$ syringe-driven filter on the top. The sample solution was quickly transferred into a clear weighted vial $\left(m_{0}\right)$. The vial was quickly and tightly sealed and weighted $\left(m_{1}\right)$. The solution was dried under vacuum circumstance at $313.15 \mathrm{~K}$ for $12 \mathrm{~h}$ to a constant weight. The vial after drying was 
reweighted $\left(m_{2}\right)$ to determine the residue solid mass. The molar solubility of the solid, $x_{1}$ in the pure solvent can be calculated by Eq. (22):

$$
\mathrm{x}_{1}=\frac{\left(\mathrm{m}_{2}-\mathrm{m}_{0}\right) / \mathrm{M}_{1}}{\left(\mathrm{~m}_{2}-\mathrm{m}_{0}\right) / \mathrm{M}_{1}+\left(\mathrm{m}_{1}-\mathrm{m}_{2}\right) / \mathrm{M}_{2}}
$$

To calculate $x_{1}$ in the binary mixing solvents, the following equation can be used:

$$
\mathrm{x}_{1}=\frac{\left(\mathrm{m}_{2}-\mathrm{m}_{0}\right) / \mathrm{M}_{1}}{\left(\mathrm{~m}_{2}-\mathrm{m}_{0}\right) / \mathrm{M}_{1}+\left(\mathrm{m}_{1}-\mathrm{m}_{2}\right) \cdot \mathrm{x}_{\mathrm{m}} / \mathrm{M}_{2}+\left(\mathrm{m}_{1}-\mathrm{m}_{2}\right) \cdot\left(1-\mathrm{x}_{\mathrm{m}}\right) / \mathrm{M}_{3}}
$$

where $M_{1}$ is molecular weight of $G S, M_{2}$ and $M_{3}$ are molecular weight of the corresponding solvents, and $x_{\mathrm{m}}$ is mass fraction of organic solvent in the mixing solvents.

Melting points of raw GS and GS equilibrated in different binary solvent mixtures were measured by a DSC25-27 (module 910, NETZSCH, Germany) equipped with a data station (Thermal Analyst 204, NETZSCH, Germany) under a nitrogen atmosphere. About $5 \mathrm{mg}$ of GS was firstly placed in sealed aluminum pans (Aluminum capsules, 00026763, Perkin-Elmer model), the temperature was then heated from 313.15 to $613.15 \mathrm{~K}$ at fixed heating rate of $10 \mathrm{~K} / \mathrm{min}$. The uncertainty of DSC measurement was lower than $2 \%$. Similar as DSC measurement, the weight loss of each sample was measured using a TGA (TA, Q5000) under a nitrogen atmosphere. IR spectra were determined by an FTIR (Bruker, TENSOR 27). About $2 \mathrm{mg}$ of each sample was first mixed with $400 \mathrm{mg}$ $\mathrm{KBr}$ powder, and then the samples were pressed into a slice with a diameter of 13 mm for IR spectroscopy. Powder X-ray diffraction (PXRD, D/MAX 2500) was used 
with a $\mathrm{Cu}$ Ka radiation source $(1.5405 \AA, 40 \mathrm{kV}, 100 \mathrm{~mA})$ at a fixed $2 \theta$ rate of $10 \%$ min. The crystal habits were observed under an optical microscope (Olympus, BX51).

\section{Results and discussions}

Tables 2-4 show the solubility of GS in three binary mixed solvents from $288.15 \mathrm{~K}$ to $318.15 \mathrm{~K}$. Figs. $2-4$ show that in all systems, the solubility of GS increased with an increase in temperature, as expected, because of endothermic dissolution process. The solubility decreased with increasing composition of the organic solvent in the solvent mixtures at a constant temperature, detailed in supplementary material (Figs. S1-S3). At the same temperature, the solubility of GS in water was about 100 times higher than in pure methanol, 400 times higher than in pure ethanol, and about 800 times higher than in pure n-propanol. The solubility in the binary solvent with same molar fraction of water was in order: in npropanol < in ethanol < in methanol, which was same order as in pure solvent, detailed in supplementary material (Figs. S4-S6). The polarity of these organic solvents are in the order: n-propanol < ethanol < methanol, which is in consistent with the order of the solubility in these solvents. Within the temperature range $288.15-318.15 \mathrm{~K}$, the solubility in water and in methanol increased about 2 times, and the solubility in propanol and ethanol increased about 5 times and 7 times, respectively.

The solubility data were fitted by the modified Apelblat equation, Jouyban- 
Acree model, Wilson model, and NRTL model, the results are listed in Tables 2-4. The corresponding accuracy of the calculated solubility based on different models were assessed using mean absolute percentage deviation (MAPD), which is defined by

$$
M A P D=\frac{1}{N} \sum_{i=1}^{N}\left(\left|\frac{x_{1, i}-x_{1, i}^{c a l}}{x_{1, i}}\right|\right) \times 100
$$

where $x_{1, j}, x_{1, j}^{\text {cal }}$ and $N$ are the measured and the calculated mole fraction solubility of GS, and number of repeated experiments, respectively. Based on the solubility, the overall calculated MAPDs as well as the parameters regressed based on different models, listed in Tables 5-8. As the Jouyban-Acree model gave the best fitting (dots in Figs. 2-4), it was suggested to be used in the design and control of the industrial crystallization process.

DSC curves of crystal samples in the different solvent mixtures at same volume fraction were almost identical, shown in Fig. 5. Same endothermic peak was observed for each crystal sample, and the onset melting point was about 466.15 K. The FTIR curves in Fig. 6 and PXRD curves in Fig. 7 were all consistent with each other, respectively. The results from PXRD, FTIR and DSC indicate only one polymorph in this work. In addition, as shown in, the crystal samples of the raw materials and in the different solvent mixtures had the similarly flaky shape (Fig. 7). It is noticed that there were differences on few small PXRD peaks, and the differences on the intensities of the peaks, which were mainly due to the orientations and amorphous phase of the raw sample and the crystal samples in different solvent mixtures. Because of the consistent DSC curves of the crystal 
samples from different solvents, only one crystal sample from in water-methanol solvent was measured by TGA. Mass of the sample started to decrease at about 478.49 K (Fig. 8), indicating the melting process of GS was accompanied by a decomposition process. Due to the combinations of melting and decomposition process, it was not possible to determine the accurate melting enthalpy of GS in this work.

Table 9 shows the estimated activity coefficient of GS in different pure solvents based on the NRTL model. The activity coefficient increased with increasing temperature in each solvent. At the same temperature, the activity coefficient followed the order: in water $<$ in methanol $<$ in ethanol $<$ in n-propanol. Kristl [29] suggested that, the molecular interactions between solute and solvent molecules can be described by

$$
\ln \gamma=\frac{\left(\mathrm{w}_{11}+\mathrm{w}_{22}-2 \mathrm{w}_{12}\right) \mathrm{V}_{2} \varphi_{1}^{2}}{\mathrm{RT}}
$$

where $w_{11}, w_{22}$, and $w_{12}$ represent solvent-solvent, solute-solute and solvent-solute interaction energies, respectively. $V_{2}$ and $\varphi_{1}$ are molar volume of subcooled liquid solute and volume fraction of the solvent. For relatively low solubility, the term $\left(V_{2} \varphi_{1}{ }^{2} / R T\right)$ in the equation can be considered as a constant. Thus, the values of $V$ in different pure solvent were mainly depended on the values of $w_{11}, w_{22}$, and $w_{12}$. At the same temperature ( $w_{22}$ is constant), $y$ in different solvents increased in the order of: in water < in methanol < in ethanol < in n-propanol. Based on Eq. (25), the results of $w_{12}$ the solute-solvent molecular interactions followed the order: in n-propanol < in ethanol < in methanol < in water, which was consistent with the 
solubility results.

Tables 10-12 show the mixing Gibbs free energy, $\Delta_{\text {mix }} G$, mixing enthalpy, $\Delta_{\text {mix }} H$, and mixing entropy, $\Delta_{\text {mix }} S$. In each solvent mixture, mixing enthalpy $\Delta_{\text {mix }} H$ tended to increase with increase in the compositions of each organic solvent, respectively. With increase in the compositions of each organic solvent (when $x_{2}$ $<0.5)$, mixing Gibbs free energy $\Delta_{\text {mix }} G$ decreased, but $\Delta_{\text {mix }} G$ was higher when $x_{2}$ $=0.73$ than $\mathrm{x}_{2}=0.48 . \Delta_{\mathrm{mix}} S$ had the opposite trends of $\Delta_{\mathrm{mix}} G$ for each solvent mixture, respectively. All $\Delta_{\text {mix }} G$ and $\Delta_{\text {mix }} H$ were negative, indicating that the mixing of water and organic solvents and GS was an endothermic process as expected. The trends of $\Delta_{\mathrm{mix}} S$ and $\Delta_{\mathrm{mix}} G$ showed interactions of $\mathrm{GS}$, water and organic solvents were strongly dependent on the mixing ratios, and the similar trends were also reported in other systems of mixing water and organic solvents [30]. The complicated trends was probably due to hydrogen-bonding interactions between organic solvents, water and solutes, forming water clusters, organic solvent clusters or solvation shells[31] in the solutions, which needs to be further investigated by the simulations [32].

The phase diagram and solubility contribute to a successful design of the crystallization process. In case of GS, a cooling crystallization from $318.15 \mathrm{~K}$ to $288.15 \mathrm{~K}$ could only result in a yield about $56 \%$, and if methanol, ethanol and propanol are applied as antisolvents [33], adding into aqueous solution of GS, the yield can be obviously increased. For example, in the system with methanol and water, when the molar fraction of water in the mixture solvent decrease from $100 \%$ 
to $20 \%$, the yield is drove up to more than $97 \%$.

\section{Conclusions}

Mole fraction solubility of D-glucosamine 2-sulfate sodium salt in water was in the range of $3-7 \times 10^{-2}$ from $288.15 \mathrm{~K}$ to $318.15 \mathrm{~K}$, which was about $0.48-1.17$ $\mathrm{g} / \mathrm{g}$ water. With adding of methanol, ethanol and propanol the solubility highly decreased into the range of $4-70 \times 10^{-5}$. The solubility at same temperature followed the order: in water $>>$ in methanol $>$ in ethanol $>$ in propanol, and the solubility in these organic solvents was about three orders lower than the solubility in water, indicating that the methanol, ethanol and propanol can be used to highly increase the yield of D-glucosamine 2-sulfate sodium salt in industrial crystallization process. At the same temperature, the solute-solvent molecular interactions was in the order: in n-propanol < in ethanol < in methanol < in water, which was consistent with the solubility in these solvents or binary solvent mixtures. Correlations with NRTL model shows that the dissolution of GS in the all solvent mixtures was endothermic and entropy-driving process. Onset melting temperature was $466.15 \mathrm{~K}$, but it is uncertain about the melting enthalpy due to the combination of the melting and decomposition process.

\section{Acknowledgments}

Authors thank for the financial support by the National Natural Science 
Foundation of China (NSFC, No. 21406071), the Open Project of State Key Laboratory of Chemical Engineering (SKL-ChE-16C03), and Hisun Co. Ltd.

\section{List of symbols}

$\begin{array}{ll}A_{\mathrm{i}} & \text { constants of Jouyban-Acree model } \\ x_{1} & \text { molar fraction of solute in solution, mol/mol } \\ x_{2} & \text { molar fraction of organic solvent in binary solvent mixtures, } \mathrm{mol} / \mathrm{mol} \\ x_{3} & \text { molar fraction of water in binary solvent mixtures, mol } / \mathrm{mol} \\ x_{\mathrm{m}} & \text { mass fraction of organic solvent in binary solvent mixtures } \\ \gamma_{1} & \text { solute activity coefficient } \\ m_{0} & \text { mass of the container, } \mathrm{g} \\ m_{1} & \text { mass of the solute and container, } \mathrm{g} \\ m_{2} & \text { mass of the solvent and container, } \mathrm{g} \\ M_{1} & \text { corresponding molar mass of the solute, } \mathrm{g} / \mathrm{mol} \\ M_{2} & \text { corresponding molar mass of the ethanol solvent, } \mathrm{g} / \mathrm{mol} \\ M_{3} & \text { corresponding molar mass of the water solvent, } \mathrm{g} / \mathrm{mol} \\ R & \text { gas constant, } \mathrm{J} / \mathrm{mol} \mathrm{K} \\ T & \text { absolute temperature, } \mathrm{K} \\ T_{\mathrm{m}} & \text { melting temperature, } \mathrm{K} \\ \Delta G_{\text {mix }} & \text { Gibbs energy of mixing, } \mathrm{kJ} / \mathrm{mol} \\ \Delta H_{\text {mix }} & \text { enthalpy of mixing, } \mathrm{kJ} / \mathrm{mol} \\ \Delta S_{\text {mix }} & \text { entropy of mixing, } \mathrm{J} / \mathrm{mol} \mathrm{K}\end{array}$

\section{References}

[1] N. Ivanovska, P. Dimitrova, Bone resorption and remodeling in murine collagenase-induced osteoarthritis after administration of glucosamine, Arthritis Res. Ther. 13 (2011) R44.

[2] C. Bassleer, L. Rovati, P. Franchimont, Stimulation of proteoglycan production by glucosamine sulfate in chondrocytes isolated from human osteoarthritic articular cartilage in vitro, Osteoarthr. Cartil. 6 (1998) 427-434.

[3] R. Chiusaroli, T. Piepoli, T. Zanelli, P. Ballanti, M. Lanza, L.C. Rovati, G. Caselli, Experimental pharmacology of glucosamine sulfate, Int. J. Rheumatol. 2011 
(2011).

[4] M. Piperno, P. Reboul, M.P. Hellio Le Graverand, M.J. Peschard, M. Annefeld, M. Richard, E. Vignon, Osteoarthritic cartilage fibrillation is associated with a decrease in chondrocyte adhesion to fibronectin, Osteoarthr. Cartil. 6 (1998) 393-399.

[5] W. Noack, M. Fischer, K.K. Förster, L.C. Rovati, I. Setnikar, Glucosamine sulfate in osteoarthritis of the knee, Osteoarthr. Cartil. 2 (1994) 51-59.

[6] L.C. Rovati, F. Girolami, M. D’Amato, G. Giacovelli, Effects of glucosamine sulfate on the use of rescue non-steroidal anti-inflammatory drugs in knee osteoarthritis: Results from the Pharmaco-Epidemiology of GonArthroSis (PEGASus) study, Semin. Arthritis Rheum. 45 (2016) S34-S41.

[7] E. Shahine, A. Elhadidi, AB0776 Efficacy of Glucosamine Sulphate in Lowering Serum Level of Interleukin-1 $\beta$ in Symptomatic Primary Knee Osteoarthritis: Clinical and Laboratory Study, Ann. Rheum. Dis. 73 (2014) 1061.1-1061.

[8] D. Wan, United States patent, Geothermics. 14 (1985) 595-599.

[9] A. Hatefi, E. Rahimpour, T. Ghafourian, F. Martinez, M. Barzegar-Jalali, A. Jouyban, Solubility of ketoconazole in N-methyl-2-pyrrolidone + water mixtures at $\mathrm{T}=(293.2$ to 313.2$) \mathrm{K}$, J. Mol. Liq. 281 (2019) 150-155.

[10] A. Hatefi, A. Jouyban, E. Mohammadian, W.E. Acree, E. Rahimpour, Prediction of paracetamol solubility in cosolvency systems at different temperatures, J. Mol. Liq. 273 (2019) 282-291.

[11] Mai W, Zuo Y, Zhang X, et al. A versatile bottom-up interface self-assembly 
strategy to hairy nanoparticle-based 2D monolayered composite and functional nanosheets. Chem. Commun. 55(2019) 10241-10244.

[12] Zheng Z, Zhang X, Carbo D, et al. Sonication-assisted synthesis of polyelectrolyte-coated curcumin nanoparticles. Langmuir. 26(2010) 7679-7681.

[13] Pattekari P, Zheng Z, Zhang X, et al. Top-down and bottom-up approaches in production of aqueous nanocolloids of low solubility drug paclitaxel. Phys Chem Chem Phys. 13(2011) 9014-9019.

[14] S. Sareen, G. Mathew, L. Joseph, Improvement in solubility of poor watersoluble drugs by solid dispersion, Int. J. Pharm. Investig. 2 (2012) 12.

[15] B.C. Hancock, P. York, R.C. Rowe, The use of solubility parameters in pharmaceutical dosage form design, Int. J. Pharm. 148 (1997) 1-21.

[16] H. Yang, J. Thati, Å.C. Rasmuson, Thermodynamics of molecular solids in organic solvents, J. Chem. Thermodyn. 48 (2012) 150-159.

[17] Y. Liu, Y. Wang, Y. Liu, S. Xu, M. Chen, S. Du, J. Gong, Solubility of L-histidine in different aqueous binary solvent mixtures from $283.15 \mathrm{~K}$ to $318.15 \mathrm{~K}$ with experimental measurement and thermodynamic modelling, J. Chem. Thermodyn. 105 (2017) 1-14.

[18] R. Thakuria, A. Delori, W. Jones, M.P. Lipert, L. Roy, N. Rodríguez-Hornedo, Pharmaceutical cocrystals and poorly soluble drugs, Int. J. Pharm. 453 (2013) $101-125$

[19] A.N. Saleemi, C.D. Rielly, Z.K. Nagy, Monitoring of the combined cooling and antisolvent crystallisation of mixtures of aminobenzoic acid isomers using ATR- 
UV/vis spectroscopy and FBRM, Chem. Eng. Sci. 77 (2012) 122-129.

[20] H. Yang, Å.C. Rasmuson, Investigation of batch cooling crystallization in a liquidliquid separating system by PAT, Org. Process Res. Dev. 16 (2012) 1212-1224.

[21] X. Zhang, G. Qian, R. Wang, X. Yang, L. Hao, H. Wei, X. Zhou, Correlation of solubility and calculation of thermodynamic properties of guanidine nitrate in different solvents, Fluid Phase Equilib. 388 (2015) 59-65.

[22] A. Jouyban, W.E. Acree, Mathematical derivation of the Jouyban-Acree model to represent solute solubility data in mixed solvents at various temperatures, J. Mol. Liq. 256 (2018) 541-547.

[23] E. Mohamadian, S. Hamidi, F. Martínez, A. Jouyban, Solubility prediction of deferiprone in $\mathrm{N}$-methyl-2-pyrrolidone + ethanol mixtures at various temperatures using a minimum number of experimental data, Phys. Chem. Liq. 55 (2017) 805-816.

[24] M. Barzegar-Jalali, E. Rahimpour, W.E. Acree, A. Jouyban, A global version of modified Wilson model for solubility prediction of drugs in methanol + water mixtures, J. Mol. Liq. 269 (2018) 609-618.

[25] Z. Han, H. Hao, H. Wu, Q. Liu, S. Zong, X. Huang, Solubility and thermodynamic properties of dirithromycin form A and form B in pure solvents and binary solvent mixture, J. Chem. Thermodyn. 132 (2019) 240-249.

[26] N.A. Bowden, D.M. Sevillano, J.P.M. Sanders, M.E. Bruins, Modelling the effects of ethanol on the solubility of the proteinogenic amino acids with the NRTL, Gude and Jouyban-Acree models, Fluid Phase Equilib. 459 (2018) 158-169. 
[27] W.E. Acree, Commentary on "solubility and solution thermodynamics of cetilistat in water and (acetone, isopropyl alcohol, acetonitrile) binary solvent mixtures," J. Mol. Liq. 230 (2017) 518-519.

[28] Yang $\mathrm{H}$, Rasmuson $\AA \mathrm{C}$, Solubility of butyl paraben in methanol, ethanol, propanol, ethyl acetate, acetone, and acetonitrile, J. Chem. Eng. Data. 55(2010) $5091-5093$.

[29] A. Kristl, G. Vesnaver, Thermodynamic investigation of the effect of octanolwater mutual miscibility on the partitioning and solubility of some guanine derivatives, J. Chem. Soc. Faraday Trans. 91 (1995) 995-998.

[30] Wakisaka A, Abdoul-Carime H, Yamamoto $\mathrm{Y}$, et al, Non-ideality of binary mixtures Water-methanol and water-acetonitrile from the viewpoint of clustering structure. Journal of the Chemical Society, Faraday Transactions. 94(1998) 369374.

[31] Yang H, Svard M, Zeglinski J, et al, Influence of solvent and solid-state structure on nucleation of parabens. Crystal Growth \& Design. 14(2014) 3890-3902.

[32] A. Anand, G.N. Patey, Molecular dynamics simulation of aspirin dissolution, J. Mol. Liq. 270 (2018) 243-250.

[33] S.M. Abuzar, S.-M. Hyun, J.-H. Kim, H.J. Park, M.-S. Kim, J.-S. Park, S.-J. Hwang, Enhancing the solubility and bioavailability of poorly water-soluble drugs using supercritical antisolvent (SAS) process, Int. J. Pharm. 538 (2018) 1-13. 


\section{Captions of figures}

Fig. 1. The molecular structure of D-glucosamine 2-sulfate sodium salt.

Fig. 2. Mole fraction solubility of D-glucosamine 2-sulfate sodium salt in the (watermethanol) binary mixtures.

Fig. 3 Mole fraction solubility of D-glucosamine 2-sulfate sodium salt in the (waterethanol) binary mixtures.

Fig. 4 Mole fraction solubility of D-glucosamine 2-sulfate sodium salt in the (water-npropanol) binary mixtures.

Fig. 5 DSC curves of D-glucosamine 2-sulfate sodium salt.

Fig. 6 FTIR spectra of D-glucosamine 2-sulfate sodium salt.

Fig. 7 PXRD spectra and microscope images of D-glucosamine 2-sulfate sodium salt

Fig. 8 TGA curve of D-glucosamine 2-sulfate sodium salt. 


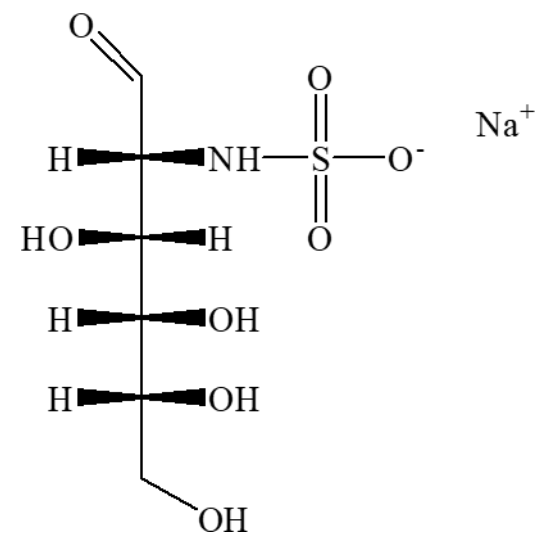

Figure 1 The molecular structure of D-glucosamine 2-sulfate sodium salt

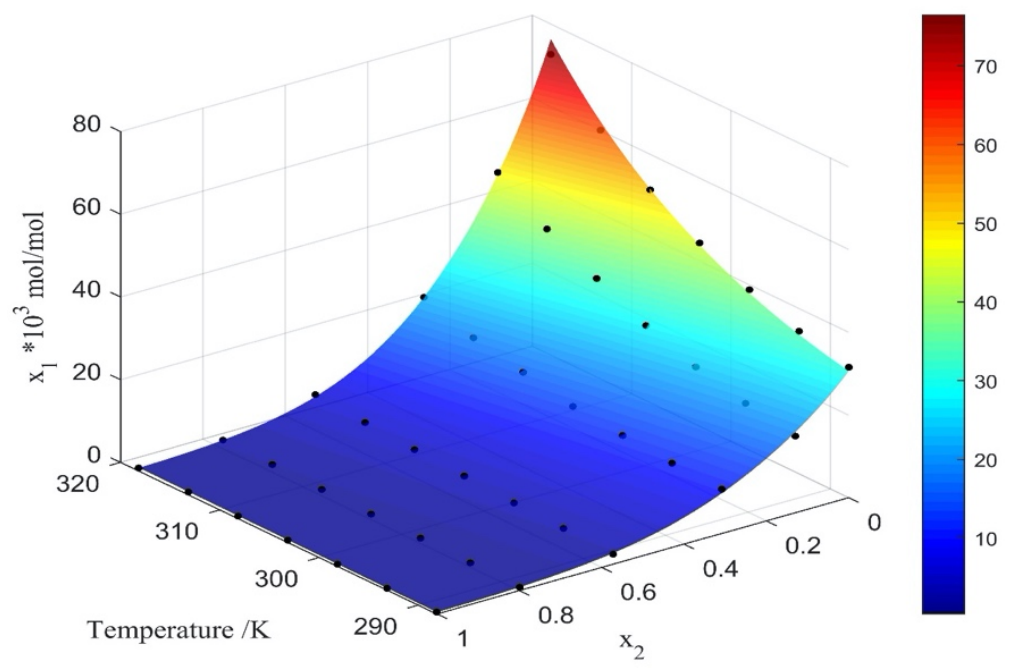

Figure 2 Mole fraction solubility of D-glucosamine 2-sulfate sodium salt in the (water-methanol) binary mixtures with Jouyban-Acree model. 


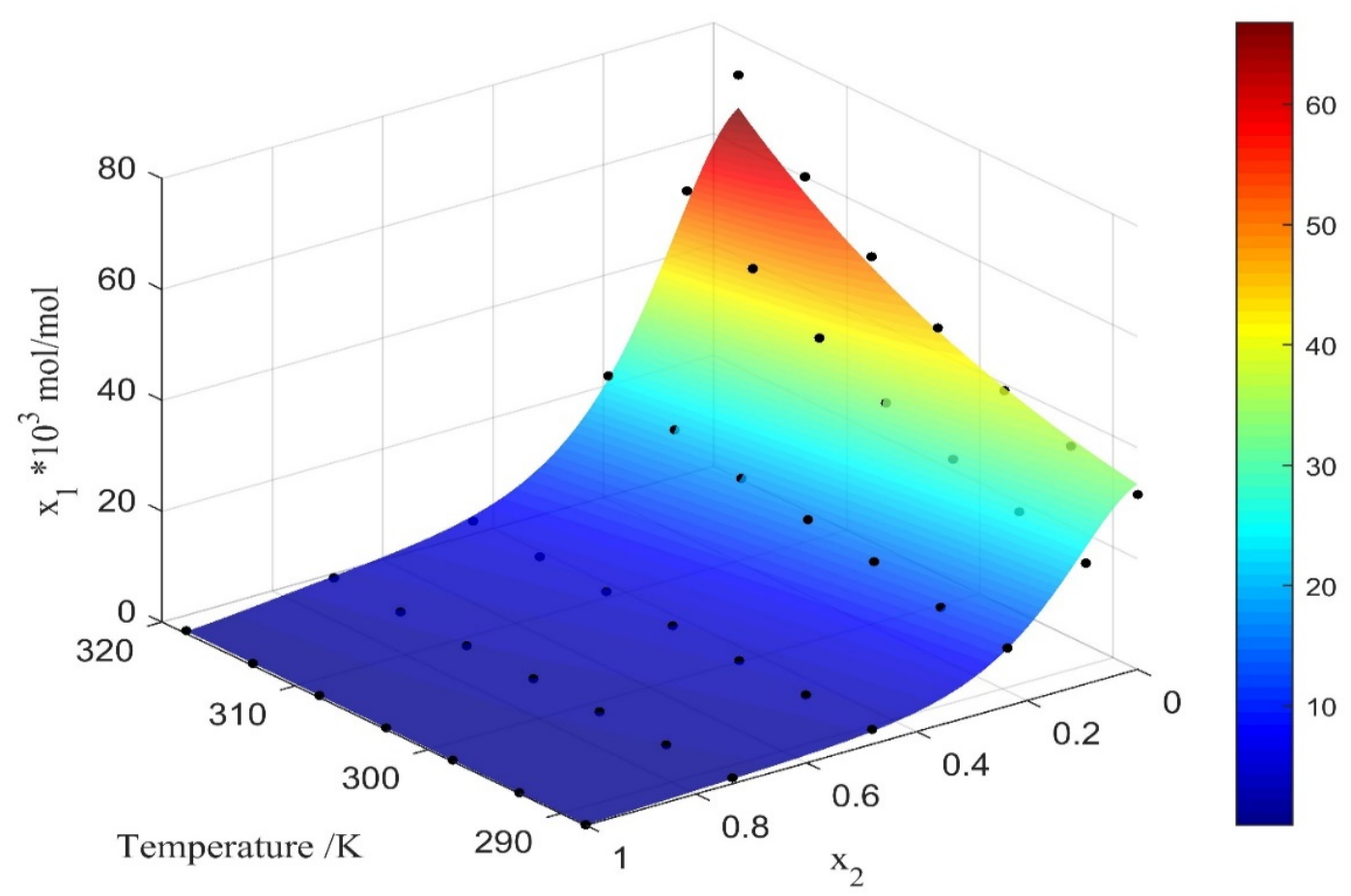

Figure 3 Mole fraction solubility of D-glucosamine 2-sulfate sodium salt in the (water-ethanol) binary mixtures with Jouyban-Acree model.

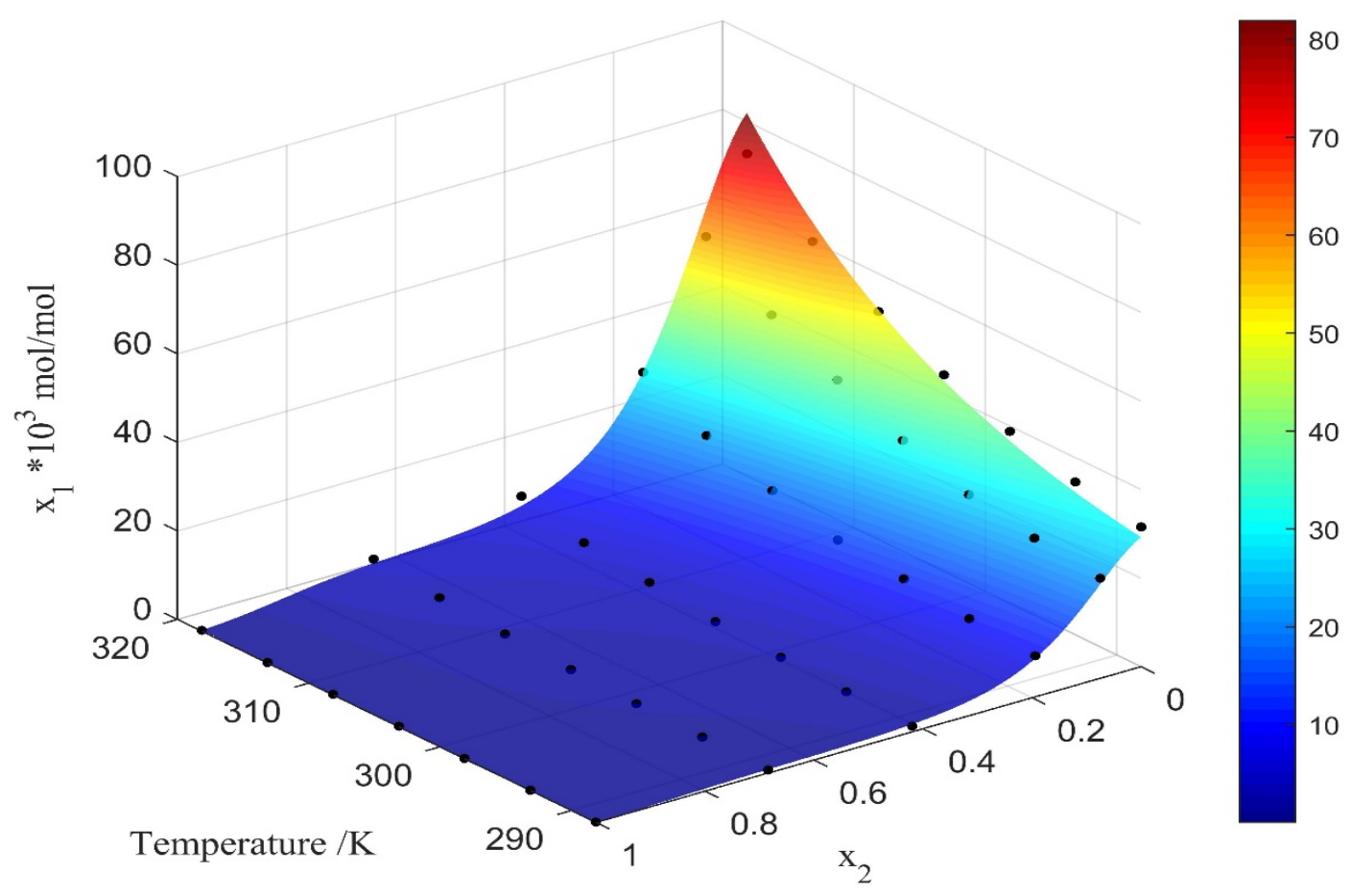

Figure 4 Mole fraction solubility of D-glucosamine 2-sulfate sodium salt in the (water-n-propanol) binary mixtures with Jouyban-Acree model. 


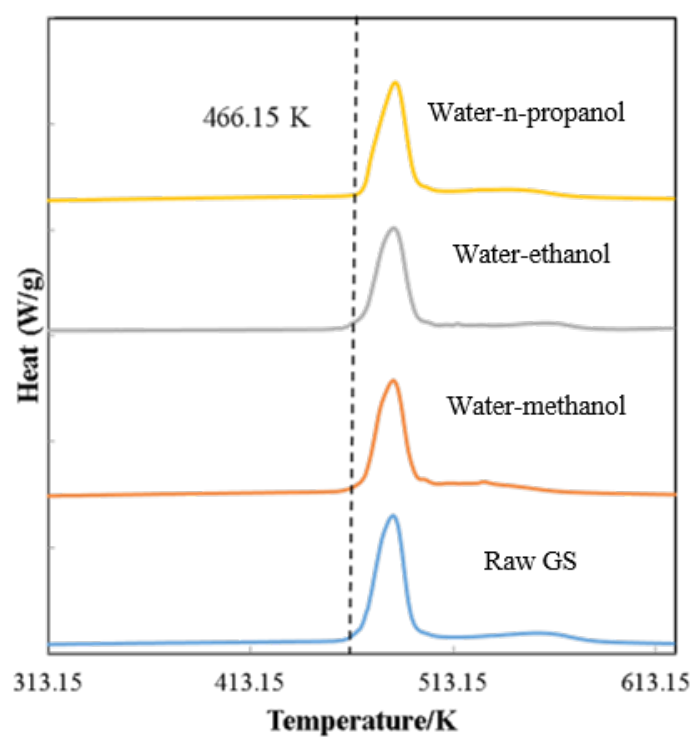

Figure 5 DSC curves of D-glucosamine 2-sulfate sodium salt with dashed lines marking onset melting points, from bottom to top: raw materials, crystal sample in water-methanol mixture, in water-ethanol mixture, in water-propanol mixture.

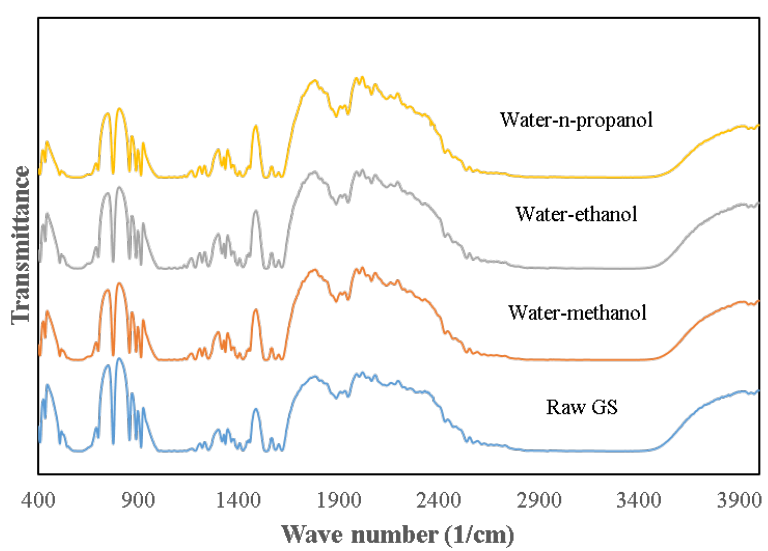

Figure 6 FTIR spectra of D-glucosamine 2-sulfate sodium from bottom to top: raw materials, crystal sample in water-methanol mixture, in water-ethanol mixture, in water-propanol mixture 


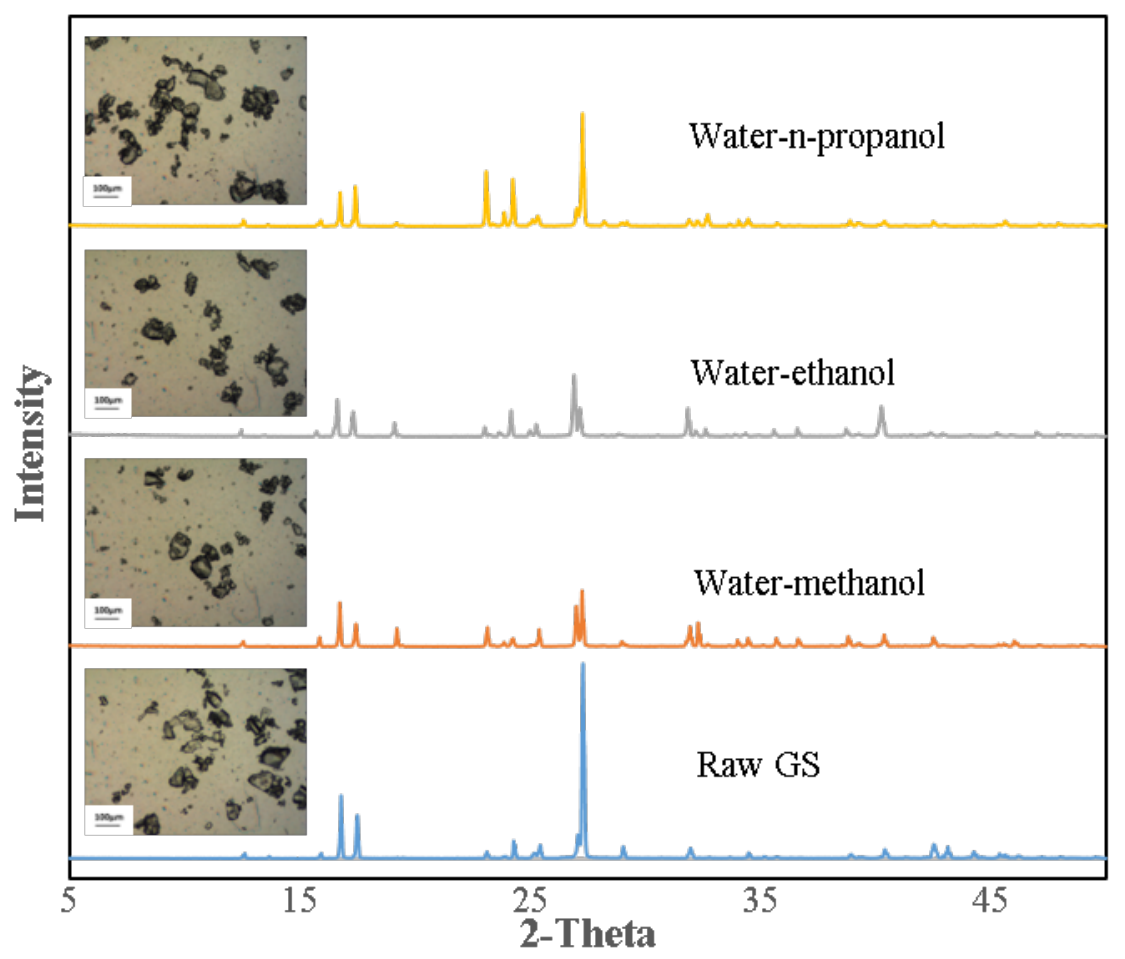

Figure 7 PXRD spectra and microscope images of D-glucosamine 2-sulfate sodium salt from bottom to top: raw materials, crystal sample in water-methanol mixture, in water-ethanol mixture, in water-propanol mixture

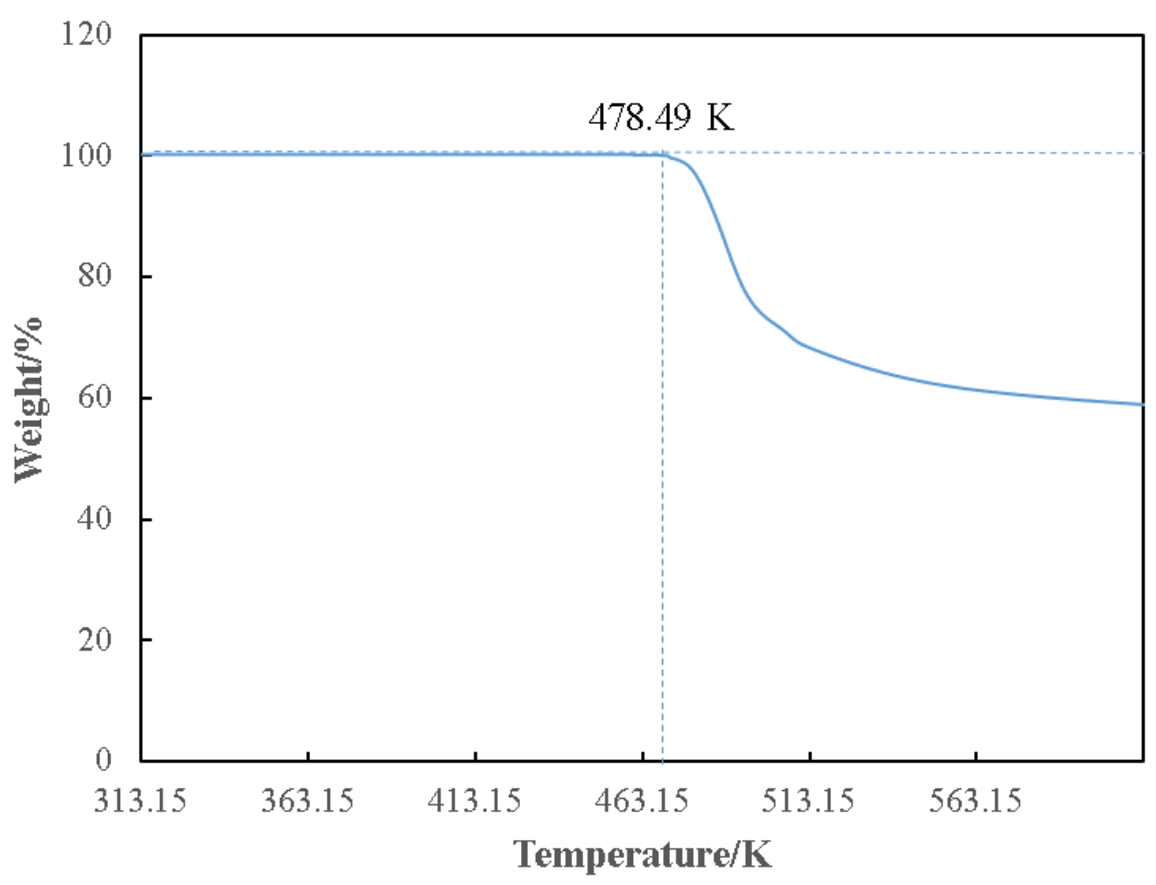

Figure 8 TGA curve of. D-glucosamine 2-sulfate sodium salt crystal sample in water-methanol mixture 


\section{Captions of tables}

Table 1 Source and purities of chemicals.

Table 2 Mole fraction solubility $(x)$ of D-glucosamine 2-sulfate sodium salt in the (water+methanol) binary mixtures at temperature $T$ and pressure $p=0.1 \mathrm{MPa}$.

Table 3 Mole fraction solubility $(x)$ of D-glucosamine 2-sulfate sodium salt in the (water+ethanol) binary mixtures at temperature $T$ and pressure $p=0.1 \mathrm{MPa}$.

Table 4 Mole fraction solubility $(x)$ of D-glucosamine 2-sulfate sodium salt in the (water+n-propanol) binary mixtures at temperature $T$ and pressure $p=0.1 \mathrm{MPa}$.

Table 5 Estimated parameters of the modified Apelblat equation for D-glucosamine 2-sulfate sodium salt in the binary solvent mixtures.

Table 6 Estimated parameters of Jouyban-Acree model for D-glucosamine 2sulfate sodium salt in the binary solvent mixtures.

Table 7 Estimated parameters of Wilson model for D-glucosamine 2-sulfate sodium salt in the binary solvent mixtures.

Table 8 Estimated parameters of NRTL model for D-glucosamine 2-sulfate sodium salt in the binary solvent mixtures.

Table 9 Estimated activity coefficient of D-glucosamine sulfate sodium in different pure solvent based on NRTL model.

Table 10 The mixing thermodynamic properties of D-glucosamine 2-sulfate sodium salt in the (water+methanol) binary mixtures at temperature $T$ and pressure $p=0.1$ MPa.

Table 11 The mixing thermodynamic properties of D-glucosamine 2-sulfate sodium 
salt in the (water+ethanol) binary mixtures at temperature $T$ and pressure $p=0.1$ $\mathrm{MPa}$

Table 12 The mixing thermodynamic properties of D-glucosamine 2-sulfate sodium salt in the (water+n-propanol) binary mixtures at temperature $T$ and pressure $p=0.1 \mathrm{MPa}$.

Table 1 Source and purities of chemicals. ${ }^{*}$

\begin{tabular}{ccccc}
\hline Chemical name & Source & Mass purity & Purification method & $\begin{array}{c}\text { Analysis } \\
\text { method }\end{array}$ \\
\hline $\begin{array}{c}\text { D-glucosamine 2-sulfate } \\
\text { sodium salt }\end{array}$ & Hisun Co. Ltd. & 0.995 & NA & HPLC \\
Methanol & Shanghai titan & 0.995 & NA & GC \\
Ethanol & Shanghai titan & 0.995 & NA & GC \\
N-propanol & Shanghai titan & 0.995 & NA & GC \\
\hline
\end{tabular}

* Standard uncertainty for mass fraction $u$ is $u(\mathrm{c})= \pm 0.001$.

Table 2 Mole fraction solubility $\left(x_{1}\right)$ of D-glucosamine 2-sulfate sodium salt in the (water-methanol) binary mixtures at temperature $T$ and pressure $p=0.1 \mathrm{MPa}$. *

\begin{tabular}{cccccc}
\hline$x_{2}$ & $x_{1}{ }^{\mathrm{exp} \times 10^{3}}$ & $\begin{array}{c}\text { Apelblat } \\
x_{1}^{\text {cal }} \times 10^{3}\end{array}$ & $\begin{array}{c}\text { Jouyban-Acree } \\
x_{1}{ }^{\text {cal }} \times 10^{3}\end{array}$ & $\begin{array}{c}\text { Wilson } \\
x_{1}{ }^{\text {cal }} \times 10^{3}\end{array}$ & $\begin{array}{c}\mathrm{NRTL} \\
x_{1}{ }^{\text {cal }} \times 10^{3}\end{array}$ \\
\hline $\mathrm{T}=288.15 \mathrm{~K}$ & & & & & \\
0.00 & $31.52(0.61)$ & 31.54 & 30.57 & 29.33 & 34.83 \\
0.13 & $18.51(0.62)$ & 18.26 & 19.49 & 19.15 & 21.01 \\
0.30 & $10.67(0.48)$ & 10.67 & 9.72 & 7.54 & 9.14 \\
0.57 & $2.41(0.23)$ & 2.41 & 2.66 & 0.76 & 2.20 \\
0.80 & $0.80(0.17)$ & 0.79 & 0.80 & 0.23 & 0.69 \\
1.00 & $0.40(0.32)$ & 0.40 & 0.38 & 0.19 & 0.23 \\
$\mathrm{~T}=293.15 \mathrm{~K}$ & & & & & \\
0.00 & $34.53(0.92)$ & 34.61 & 33.60 & 33.52 & 37.90 \\
0.13 & $20.73(0.74)$ & 20.84 & 21.48 & 22.73 & 23.34 \\
0.30 & $11.25(0.69)$ & 11.22 & 10.84 & 10.06 & 10.56
\end{tabular}




\begin{tabular}{|c|c|c|c|c|c|}
\hline 0.57 & $2.87(0.54)$ & 2.85 & 3.02 & 1.32 & 2.65 \\
\hline 0.80 & $0.90(0.34)$ & 0.92 & 0.93 & 0.42 & 0.81 \\
\hline 1.00 & $0.46(0.19)$ & 0.46 & 0.45 & 0.28 & 0.27 \\
\hline \multicolumn{6}{|c|}{$\mathrm{T}=298.15 \mathrm{~K}$} \\
\hline 0.00 & $38.77(0.83)$ & 38.74 & 37.88 & 38.04 & 41.29 \\
\hline 0.13 & $23.74(0.71)$ & 24.08 & 24.23 & 26.71 & 26.07 \\
\hline 0.30 & $12.21(0.79)$ & 12.19 & 12.26 & 12.97 & 12.19 \\
\hline 0.57 & $3.30(0.49)$ & 3.35 & 3.44 & 2.19 & 3.20 \\
\hline 0.80 & $1.10(0.28)$ & 1.07 & 1.06 & 0.84 & 0.99 \\
\hline 1.00 & $0.52(0.12)$ & 0.52 & 0.51 & 0.40 & 0.40 \\
\hline \multicolumn{6}{|c|}{$\mathrm{T}=303.15 \mathrm{~K}$} \\
\hline 0.00 & $44.36(0.77)$ & 44.19 & 43.73 & 43.00 & 45.02 \\
\hline 0.13 & $28.01(0.62)$ & 28.15 & 27.85 & 31.10 & 29.08 \\
\hline 0.30 & $13.46(0.58)$ & 13.66 & 14.03 & 16.38 & 14.11 \\
\hline 0.57 & $3.99(0.40)$ & 3.95 & 3.93 & 3.47 & 3.90 \\
\hline 0.80 & $1.20(0.22)$ & 1.22 & 1.22 & 1.39 & 1.25 \\
\hline 1.00 & $0.58(0.03)$ & 0.58 & 0.58 & 0.60 & 0.54 \\
\hline \multicolumn{6}{|c|}{$\mathrm{T}=308.15 \mathrm{~K}$} \\
\hline 0.00 & $51.44(0.81)$ & 51.30 & 51.62 & 48.34 & 49.15 \\
\hline 0.13 & $33.61(0.77)$ & 33.27 & 32.64 & 35.97 & 32.57 \\
\hline 0.30 & $15.97(0.70)$ & 15.74 & 16.25 & 20.28 & 16.33 \\
\hline 0.57 & $4.64(0.62)$ & 4.65 & 4.51 & 5.26 & 4.78 \\
\hline 0.80 & $1.40(0.81)$ & 1.40 & 1.39 & 2.36 & 1.57 \\
\hline 1.00 & $0.64(0.06)$ & 0.64 & 0.65 & 0.80 & 0.90 \\
\hline \multicolumn{6}{|c|}{$\mathrm{T}=313.15 \mathrm{~K}$} \\
\hline 0.00 & $60.10(0.63)$ & 60.52 & 62.20 & 54.13 & 53.65 \\
\hline 0.12 & $39.88(0.51)$ & 39.73 & 38.90 & 41.29 & 36.46 \\
\hline 0.30 & $18.55(0.54)$ & 18.62 & 19.01 & 24.61 & 18.92 \\
\hline 0.57 & $5.47(0.38)$ & 5.47 & 5.19 & 7.64 & 5.85 \\
\hline 0.80 & $1.60(0.50)$ & 1.59 & 1.58 & 3.17 & 1.98 \\
\hline 1.00 & $0.70(0.32)$ & 0.70 & 0.73 & 1.04 & 1.33 \\
\hline \multicolumn{6}{|c|}{$\mathrm{T}=318.15 \mathrm{~K}$} \\
\hline 0.00 & $72.66(0.52)$ & 72.49 & 76.42 & 60.39 & 58.53 \\
\hline 0.12 & $47.74(0.61)$ & 47.89 & 47.16 & 47.19 & 40.82 \\
\hline 0.30 & $22.59(0.59)$ & 22.59 & 22.57 & 29.62 & 21.93 \\
\hline
\end{tabular}


0.57

6.43(0.27)

6.43

5.98

10.75

7.16

0.80

1.80

1.78

3.56

2.52

1.00

0.76(0.05)

0.76

0.80

1.33

1.46

* Standard uncertainties $\mathrm{u}$ are $\mathrm{u}(\mathrm{x})= \pm 0.00005, \mathrm{u}(\mathrm{T})= \pm 0.01 \mathrm{~K}$, and $\mathrm{u}(\mathrm{p})= \pm 0.0025 \mathrm{MPa}$

* In almost all cases the coefficients of variation (CV) were smaller than $2.0 \%$. 
Table 3 Mole fraction solubility ( $x 1$ ) of D-glucosamine 2-sulfate sodium salt in the (water-ethanol) binary mixtures at temperature $\mathrm{T}$ and pressure $\mathrm{p}=0.1 \mathrm{MPa}$. *

\begin{tabular}{|c|c|c|c|c|c|}
\hline$x_{2}$ & $x 1^{\exp } \times 10^{3}$ & $\begin{array}{l}\text { Apelblat } \\
x_{1}{ }^{\mathrm{cal}} \times 10^{3}\end{array}$ & $\begin{array}{c}\text { Jouyban-Acree } \\
x_{1}{ }^{\text {cal }} \times 10^{3} \\
\end{array}$ & $\begin{array}{c}\text { Wilson } \\
x_{1}^{\text {cal }} \times 10^{3} \\
\end{array}$ & NRTL $x_{1}{ }^{\text {cal }} \times 10^{3}$ \\
\hline \multicolumn{6}{|c|}{$\mathrm{T}=288.15 \mathrm{~K}$} \\
\hline 0.00 & $31.52(0.61)$ & 31.54 & 33.39 & 31.97 & 34.18 \\
\hline 0.09 & $21.81(0.42)$ & 21.93 & 24.69 & 21.33 & 21.40 \\
\hline 0.23 & $10.47(0.28)$ & 10.66 & 10.33 & 8.31 & 8.86 \\
\hline 0.48 & $2.70(0.21)$ & 2.72 & 2.31 & 0.89 & 1.83 \\
\hline 0.73 & $1.10(0.30)$ & 1.13 & 0.86 & 0.36 & 0.71 \\
\hline 1.00 & $0.08(0.10)$ & 0.08 & 0.10 & 0.10 & 0.10 \\
\hline \multicolumn{6}{|c|}{$\mathrm{T}=293.15 \mathrm{~K}$} \\
\hline 0.00 & $34.53(0.87)$ & 34.61 & 35.87 & 36.10 & 38.13 \\
\hline 0.09 & $25.33(0.79)$ & 25.12 & 27.13 & 25.10 & 24.73 \\
\hline 0.23 & $12.02(0.71)$ & 12.19 & 11.83 & 11.04 & 10.95 \\
\hline 0.48 & $3.13(0.54)$ & 3.12 & 2.84 & 1.51 & 2.46 \\
\hline 0.73 & $1.30(0.31)$ & 1.28 & 1.12 & 0.68 & 0.95 \\
\hline 1.00 & $0.12(0.15)$ & 0.13 & 0.15 & 0.15 & 0.15 \\
\hline \multicolumn{6}{|c|}{$\mathrm{T}=298.15 \mathrm{~K}$} \\
\hline 0.00 & $38.77(0.96)$ & 38.74 & 39.29 & 40.61 & 42.40 \\
\hline 0.09 & $29.03(0.73)$ & 28.98 & 30.19 & 29.18 & 28.43 \\
\hline 0.23 & $14.52(0.35)$ & 13.98 & 13.61 & 14.29 & 13.48 \\
\hline 0.48 & $3.56(0.64)$ & 3.56 & 3.45 & 2.49 & 3.32 \\
\hline 0.73 & $1.50(0.30)$ & 1.47 & 1.43 & 1.15 & 1.25 \\
\hline 1.00 & $0.21(0.19)$ & 0.19 & 0.20 & 0.16 & 0.19 \\
\hline \multicolumn{6}{|c|}{$\mathrm{T}=303.15 \mathrm{~K}$} \\
\hline 0.00 & $44.36(0.72)$ & 44.19 & 43.80 & 45.43 & 47.10 \\
\hline 0.09 & $33.40(0.60)$ & 33.65 & 33.99 & 33.67 & 32.52 \\
\hline 0.23 & $16.39(0.51)$ & 16.08 & 15.70 & 18.01 & 16.34 \\
\hline 0.48 & $4.13(0.47)$ & 4.04 & 4.15 & 3.94 & 4.38 \\
\hline 0.73 & $1.70(0.26)$ & 1.68 & 1.78 & 1.91 & 1.67 \\
\hline 1.00 & $0.27(0.33)$ & 0.27 & 0.26 & 0.25 & 0.25 \\
\hline \multicolumn{6}{|c|}{$\mathrm{T}=308.15 \mathrm{~K}$} \\
\hline 0.00 & $51.44(0.78)$ & 51.30 & 49.65 & 50.72 & 52.19 \\
\hline 0.09 & $39.41(0.64)$ & 39.30 & 38.70 & 38.61 & 37.06 \\
\hline
\end{tabular}




\begin{tabular}{cccccc}
0.23 & $18.10(0.53)$ & 18.53 & 18.17 & 22.20 & 19.65 \\
0.48 & $4.50(0.49)$ & 4.56 & 4.93 & 5.94 & 5.76 \\
0.73 & $1.90(0.32)$ & 1.93 & 2.15 & 3.05 & 2.24 \\
1.00 & $0.35(0.04)$ & 0.36 & 0.33 & 0.36 & 0.34 \\
$\mathrm{~T}=313.15 \mathrm{~K}$ & & & & \\
0.00 & $60.10(0.74)$ & 60.52 & 57.16 & 56.41 & 57.71 \\
0.09 & $46.15(0.69)$ & 46.14 & 44.51 & 44.01 & 42.04 \\
0.23 & $21.08(0.18)$ & 21.41 & 21.08 & 26.93 & 23.46 \\
0.48 & $5.06(0.65)$ & 5.11 & 5.79 & 8.64 & 7.45 \\
0.73 & $2.20(0.23)$ & 2.23 & 2.54 & 4.34 & 2.96 \\
1.00 & $0.46(0.12)$ & 0.46 & 0.39 & 0.49 & 0.46 \\
$\mathrm{~T}=318.15 \mathrm{~K}$ & & & & \\
0.00 & $72.66(0.61)$ & 72.49 & 66.78 & 62.61 & 63.68 \\
0.09 & $54.43(0.40)$ & 54.44 & 52.05 & 50.07 & 47.76 \\
0.23 & $25.04(0.32)$ & 24.78 & 24.52 & 32.25 & 27.77 \\
0.48 & $5.73(0.22)$ & 5.70 & 6.73 & 11.40 & 9.53 \\
0.73 & $2.60(0.11)$ & 2.58 & 2.93 & 5.16 & 3.89 \\
1.00 & $0.55(0.15)$ & 0.55 & 0.46 & 0.64 & 0.61 \\
\hline
\end{tabular}

* Standard uncertainties $\mathrm{u}$ are $\mathrm{u}(\mathrm{x})= \pm 0.00005, \mathrm{u}(\mathrm{T})= \pm 0.01 \mathrm{~K}$, and $\mathrm{u}(\mathrm{p})= \pm 0.0025 \mathrm{Mpa}$

* In almost all cases the coefficients of variation (CV) were smaller than $2.0 \%$. 
Table 4 Mole fraction solubility (x1) of D-glucosamine 2-sulfate sodium salt in the (water-n-propanol) binary mixtures at temperature $\mathrm{T}$ and pressure $\mathrm{p}=0.1 \mathrm{MPa}$. *

\begin{tabular}{|c|c|c|c|c|c|}
\hline$x_{2}$ & $x_{1}{ }^{\exp } \times 10^{3}$ & $\begin{array}{l}\text { Apelblat } \\
x_{1}{ }^{\text {cal }} \times 10^{3}\end{array}$ & $\begin{array}{c}\text { Jouyban- } \\
\text { Acree } \\
x_{1}{ }^{\mathrm{cal}} \times 10^{3}\end{array}$ & $\begin{array}{c}\text { Wilson } \\
x_{1}{ }^{\mathrm{cal}} \times 10^{3}\end{array}$ & $\begin{array}{c}\text { NRTL } \\
x_{1}{ }^{\text {cal }} \times 10^{3}\end{array}$ \\
\hline \multicolumn{6}{|c|}{$\mathrm{T}=288.15 \mathrm{~K}$} \\
\hline 0.00 & $31.52(0.81)$ & 31.54 & 29.24 & 31.28 & 32.34 \\
\hline 0.07 & $22.63(0.65)$ & 22.29 & 21.19 & 20.06 & 19.83 \\
\hline 0.19 & $9.33(0.76)$ & 9.39 & 8.64 & 6.96 & 7.12 \\
\hline 0.42 & $1.34(0.32)$ & 1.34 & 1.74 & 0.74 & 1.11 \\
\hline 0.68 & $0.71(0.27)$ & 0.71 & 0.83 & 0.40 & 0.60 \\
\hline 1.00 & $0.04(0.003)$ & 0.04 & 0.03 & 0.03 & 0.03 \\
\hline \multicolumn{6}{|c|}{$\mathrm{T}=293.15 \mathrm{~K}$} \\
\hline 0.00 & $34.53(0.81)$ & 34.61 & 32.18 & 35.73 & 36.74 \\
\hline 0.07 & $24.46(0.70)$ & 24.56 & 23.76 & 24.08 & 23.70 \\
\hline 0.19 & $10.49(0.34)$ & 10.40 & 10.05 & 9.74 & 9.53 \\
\hline 0.42 & $1.88(0.37)$ & 1.81 & 2.16 & 1.29 & 1.70 \\
\hline 0.68 & $1.00(0.11)$ & 0.97 & 1.08 & 0.76 & 0.88 \\
\hline 1.00 & $0.05(0.05)$ & 0.05 & 0.04 & 0.04 & 0.04 \\
\hline \multicolumn{6}{|c|}{$\mathrm{T}=298.15 \mathrm{~K}$} \\
\hline 0.00 & $38.77(0.51)$ & 38.74 & 36.62 & 40.59 & 41.57 \\
\hline 0.07 & $27.09(0.45)$ & 27.76 & 27.44 & 28.60 & 28.02 \\
\hline 0.19 & $12.28(0.21)$ & 11.99 & 11.95 & 13.07 & 12.49 \\
\hline 0.42 & $2.46(0.21)$ & 2.49 & 2.71 & 2.19 & 2.56 \\
\hline 0.68 & $1.33(0.32)$ & 1.34 & 1.43 & 1.26 & 1.32 \\
\hline 1.00 & $0.07(0.017)$ & 0.07 & 0.06 & 0.05 & 0.05 \\
\hline \multicolumn{6}{|c|}{$\mathrm{T}=303.15 \mathrm{~K}$} \\
\hline 0.00 & $44.36(0.74)$ & 44.19 & 42.96 & 45.86 & 46.85 \\
\hline 0.07 & $32.14(0.64)$ & 32.15 & 32.56 & 33.55 & 32.90 \\
\hline 0.19 & $13.82(0.47)$ & 14.35 & 14.54 & 17.02 & 16.05 \\
\hline 0.42 & $3.31(0.58)$ & 3.46 & 3.45 & 3.53 & 3.76 \\
\hline 0.68 & $1.79(0.45)$ & 1.86 & 1.88 & 2.10 & 1.94 \\
\hline 1.00 & $0.09(0.20)$ & 0.09 & 0.09 & 0.07 & 0.11 \\
\hline \multicolumn{6}{|c|}{$\mathrm{T}=308.15 \mathrm{~K}$} \\
\hline 0.00 & $51.44(0.63)$ & 51.30 & 51.88 & 51.55 & 52.63 \\
\hline 0.07 & $38.57(0.51)$ & 38.08 & 39.71 & 39.03 & 38.34 \\
\hline
\end{tabular}




\begin{tabular}{cccccc}
0.19 & $17.83(0.32)$ & 17.80 & 18.05 & 21.63 & 20.24 \\
0.42 & $5.01(0.27)$ & 4.85 & 4.43 & 5.53 & 5.44 \\
0.68 & $2.68(0.32)$ & 2.61 & 2.47 & 3.35 & 2.80 \\
1.00 & $0.11(0.06)$ & 0.12 & 0.12 & 0.14 & 0.14 \\
$\mathrm{~T}=313.15 \mathrm{~K}$ & & & & \\
0.00 & $60.10(0.81)$ & 60.52 & 64.36 & 57.78 & 58.93 \\
0.07 & $46.14(0.77)$ & 46.06 & 49.46 & 44.94 & 44.25 \\
0.19 & $23.11(0.59)$ & 22.83 & 22.74 & 26.79 & 25.00 \\
0.42 & $6.84(0.22)$ & 6.88 & 5.75 & 8.25 & 7.66 \\
0.68 & $3.65(0.28)$ & 3.67 & 3.25 & 5.19 & 3.96 \\
1.00 & $0.15(0.04)$ & 0.15 & 0.17 & 0.15 & 0.18 \\
$\mathrm{~T}=318.15 \mathrm{~K}$ & & & & & \\
0.00 & $72.66(0.43)$ & 72.49 & 81.87 & 64.49 & 65.80 \\
0.07 & $56.64(0.54)$ & 56.80 & 63.08 & 51.51 & 50.84 \\
0.18 & $30.08(0.44)$ & 30.19 & 30.25 & 33.36 & 31.21 \\
0.41 & $9.85(0.60)$ & 9.85 & 7.73 & 12.18 & 10.81 \\
0.68 & $5.20(0.49)$ & 5.20 & 4.28 & 7.71 & 5.55 \\
1.00 & $0.19(0.29)$ & 0.19 & 0.24 & 0.20 & 0.29 \\
\hline
\end{tabular}

* Standard uncertainties $\mathrm{u}$ are $\mathrm{u}(\mathrm{x})= \pm 0.00005, \mathrm{u}(\mathrm{T})= \pm 0.01 \mathrm{~K}$, and $\mathrm{u}(\mathrm{p})= \pm 0.0025 \mathrm{MPa}$

* In almost all cases the coefficients of variation (CV) were smaller than $2.0 \%$. 
Table 5 Estimated parameters of modified Apelblat equation for D-glucosamine 2-sulfate sodium salt in the binary solvent mixtures. ${ }^{*}$

\begin{tabular}{|c|c|c|c|c|}
\hline Systems & $A$ & $B$ & C & MAPD $/ \%$ \\
\hline \multicolumn{5}{|c|}{ Water-methanol } \\
\hline 0.00 & -539.20 & 22005.47 & 81.11 & 0.28 \\
\hline 0.12 & -394.10 & 15100.06 & 59.63 & 0.79 \\
\hline 0.30 & -799.99 & 33924.79 & 119.66 & 0.53 \\
\hline 0.57 & -119.23 & 2576.64 & 18.41 & 0.55 \\
\hline 0.80 & 14.46 & -3087.71 & -1.92 & 0.13 \\
\hline \multirow[t]{2}{*}{1.00} & 241.91 & -12905.25 & -36.19 & 0.18 \\
\hline & & & & $\sum(\mathrm{MAPD}) \%=2.46$ \\
\hline \multicolumn{5}{|c|}{ Water-ethanol } \\
\hline 0.00 & -539.47 & 22017.87 & 81.15 & 0.28 \\
\hline 0.09 & -262.31 & 9308.55 & 39.94 & 0.38 \\
\hline 0.23 & -168.76 & 5228.22 & 25.79 & 1.99 \\
\hline 0.48 & 46.68 & -4275.22 & -6.67 & 0.90 \\
\hline 0.73 & -192.91 & 6264.67 & 29.03 & 1.59 \\
\hline \multirow[t]{2}{*}{1.00} & 1072.02 & -53647.83 & -158.07 & 3.32 \\
\hline & & & & $\sum(\mathrm{MAPD}) \%=8.46$ \\
\hline \multicolumn{5}{|c|}{ Water-N-propanol } \\
\hline 0.00 & -539.47 & 22017.87 & 81.15 & 0.28 \\
\hline 0.07 & -676.66 & 27920.60 & 101.70 & 0.88 \\
\hline 0.19 & -1025.39 & 43003.47 & 153.88 & 1.36 \\
\hline 0.41 & -525.39 & 18238.28 & 80.42 & 1.85 \\
\hline 0.68 & -421.29 & 13528.99 & 64.82 & 1.51 \\
\hline \multirow[t]{2}{*}{1.00} & 261.37 & -16524.72 & -37.83 & 1.67 \\
\hline & & & & $\sum(\mathrm{MAPD}) \%=7.54$ \\
\hline
\end{tabular}

*Standard uncertainty for $u$ is $u(T)= \pm 0.01 \mathrm{~K}$. 
Table 6 Estimated parameters of Jouyban-Acree model for D-glucosamine 2-sulfate sodium salt in the binary solvent mixtures. *

\begin{tabular}{lccc}
\hline Parameter & Water-methanol & Water-ethanol & Water-propanol \\
\hline $\mathrm{A}_{1}$ & -666.83 & -502.22 & -844.70 \\
$\mathrm{~A}_{2}$ & 27541.58 & 20699.82 & 35265.27 \\
$\mathrm{~A}_{3}$ & 100.25 & 75.39 & 126.92 \\
$\mathrm{~A}_{4}$ & 844.67 & 1336.47 & 914.35 \\
$\mathrm{~A}_{5}$ & -37556.91 & -61278.80 & -42898.99 \\
$\mathrm{~A}_{6}$ & 238.08 & -7238.64 & -9635.95 \\
$\mathrm{~A}_{7}$ & -1919.73 & 13203.15 & 20747.96 \\
$\mathrm{~A}_{8}$ & 1423.53 & -7265.23 & -12476.22 \\
$\mathrm{~A}_{9}$ & -126.75 & -198.66 & -135.54 \\
$\sum$ (MAPD)\% & 3.00 & 7.90 & 8.81 \\
\hline
\end{tabular}

${ }^{*}$ Standard uncertainty for $\mathrm{u}$ is $\mathrm{u}(\mathrm{T})= \pm 0.01 \mathrm{~K}$.

Table 7 Estimated parameters of the Wilson model for D-glucosamine 2-sulfate sodium salt in the binary solvent mixtures. *

\begin{tabular}{cccc}
\hline Parameter/kJ/mol & Water-methanol & Water-ethanol & Water-propanol \\
\hline$\lambda_{12}-\lambda_{11}$ & 3.44 & 5.53 & 9.11 \\
$\lambda_{21}-\lambda_{22}$ & -3.43 & -4.12 & -4.85 \\
$\lambda_{13}-\lambda_{11}$ & -15.27 & -15.16 & -16.26 \\
$\lambda_{31}-\lambda_{33}$ & -1.75 & -1.90 & -1.70 \\
$\lambda_{23}-\lambda_{22}$ & -6.65 & -6.08 & -6.55 \\
$\lambda_{32}-\lambda_{33}$ & 1.43 & 0.91 & 0.80 \\
$\Sigma($ MAPD $\%$ & 29.43 & 24.72 & 15.50 \\
\hline
\end{tabular}

*Standard uncertainty for $u$ is $u(T)= \pm 0.01 \mathrm{~K}$. 
Table 8 Estimated parameters of the NRTL model for D-glucosamine 2-sulfate sodium salt in the binary solvent mixtures.

\begin{tabular}{cccc}
\hline Parameter/kJ/mol & Water-methanol & Water-ethanol & Water-propanol \\
\hline$\Delta \mathrm{g}_{12}$ & -5.03 & -4.77 & -4.82 \\
$\Delta \mathrm{g}_{21}$ & 13.65 & 10.17 & 13.52 \\
$\Delta \mathrm{g}_{13}$ & -21.17 & -19.17 & -17.89 \\
$\Delta \mathrm{g}_{31}$ & 12.17 & 4.62 & 0.66 \\
$\Delta \mathrm{g}_{23}$ & -1.40 & -1.88 & -2.41 \\
$\Delta \mathrm{g}_{32}$ & 0.25 & -0.78 & -2.11 \\
$\mathrm{a}_{12}$ & 0.90 & 0.90 & 0.90 \\
$\mathrm{a}_{13}$ & 0.10 & 0.10 & 0.10 \\
$\mathrm{a}_{23}$ & 0.30 & 0.30 & 0.30 \\
$\Sigma($ MAPD $\%$ & 15.54 & 14.73 & 8.50 \\
\hline
\end{tabular}

*Standard uncertainty for $u$ is $u(T)= \pm 0.01 \mathrm{~K}$. 
Table 9 Estimated activity coefficient of D-glucosamine sulfate sodium in different pure solvent based on NRTL model.

\begin{tabular}{ccccc}
\hline \multirow{2}{*}{$T$} & \multicolumn{3}{c}{$($ Iny $) \times 10^{4}$} \\
\cline { 2 - 5 } & Water & Methanol & Ethanol & N-propanol \\
\hline 288.15 & 0.02 & 1.12 & 4.90 & 11.92 \\
293.15 & 0.03 & 2.09 & 7.56 & 19.46 \\
298.15 & 0.05 & 3.69 & 11.31 & 30.67 \\
303.15 & 0.08 & 6.89 & 16.46 & 46.87 \\
308.15 & 0.14 & 12.08 & 23.36 & 69.55 \\
313.15 & 0.24 & 21.41 & 32.41 & 100.45 \\
318.15 & 0.45 & 37.53 & 44.02 & 141.60 \\
\hline
\end{tabular}

Table 10 The mixing thermodynamic properties of D-glucosamine 2-sulfate sodium salt in the (water+methanol) binary mixtures at temperature $T$ and pressure $p=0.1 \mathrm{MPa}$.

\begin{tabular}{|c|c|c|c|}
\hline$x_{2}$ & $\Delta_{\text {mix }} G / \mathrm{kJ} / \mathrm{mol}$ & $\Delta_{\mathrm{mix}} \mathrm{S} / \mathrm{J} / \mathrm{K} \cdot \mathrm{mol}$ & $\Delta_{\mathrm{mix}} H / \mathrm{kJ} / \mathrm{mol}$ \\
\hline \multicolumn{4}{|c|}{$\mathrm{T}=288.15 \mathrm{~K}$} \\
\hline 0.09 & -1.90 & 1.19 & -1.56 \\
\hline 0.23 & -2.21 & 3.82 & -1.11 \\
\hline 0.48 & -2.04 & 5.29 & -0.52 \\
\hline 0.73 & -1.43 & 4.04 & -0.27 \\
\hline \multicolumn{4}{|c|}{$\mathrm{T}=293.15 \mathrm{~K}$} \\
\hline 0.09 & -2.00 & 1.13 & -1.67 \\
\hline 0.23 & -2.24 & 3.85 & -1.12 \\
\hline 0.48 & -2.09 & 5.26 & -0.54 \\
\hline 0.73 & -1.45 & 4.04 & -0.27 \\
\hline \multicolumn{4}{|c|}{$\mathrm{T}=298.15 \mathrm{~K}$} \\
\hline 0.09 & -2.12 & 1.02 & -1.81 \\
\hline 0.23 & -2.30 & 3.85 & -1.16 \\
\hline 0.48 & -2.13 & 5.25 & -0.57 \\
\hline 0.73 & -1.48 & 4.03 & -0.28 \\
\hline \multicolumn{4}{|c|}{$\mathrm{T}=303.15 \mathrm{~K}$} \\
\hline 0.09 & -2.28 & 0.84 & -2.03 \\
\hline 0.23 & -2.37 & 3.83 & -1.21 \\
\hline 0.48 & -2.18 & 5.21 & -0.60 \\
\hline 0.73 & -1.51 & 4.03 & -0.29 \\
\hline
\end{tabular}


$\mathrm{T}=308.15 \mathrm{~K}$

$$
0.09
$$

$-2.48$

0.61

$-2.29$

0.23

$-2.47$

3.72

$-1.33$

0.48

$-2.23$

5.18

$-0.63$

0.73

$-1.54$

4.03

$-0.30$

$\mathrm{T}=313.15 \mathrm{~K}$

0.09

$-2.69$

0.39

$-2.57$

0.23

$-2.58$

3.63

$-1.44$

0.48

$-2.28$

5.15

$-0.67$

0.73

$-1.57$

4.03

$-0.31$

$\mathrm{T}=318.15 \mathrm{~K}$

$\begin{array}{ll}0.09 & -2.94 \\ 0.23 & -2.73 \\ 0.48 & -2.34 \\ 0.73 & -1.60\end{array}$

0.14

$-2.89$

3.47

$-1.62$

5.11

$-0.71$

4.03

$-0.32$

Table 11 The mixing thermodynamic properties of D-glucosamine 2-sulfate sodium salt in the (water+ethanol) binary mixtures at temperature $T$ and pressure $p=0.1 \mathrm{MPa}$.

\begin{tabular}{|c|c|c|c|}
\hline$x_{2}$ & $\Delta_{\mathrm{mix}} \mathrm{G} / \mathrm{kJ} / \mathrm{mol}$ & $\Delta_{\mathrm{mix}} \mathrm{S} / \mathrm{J} / \mathrm{K} \cdot \mathrm{mol}$ & $\Delta_{\text {mix }} H / \mathrm{kJ} / \mathrm{mol}$ \\
\hline \multicolumn{4}{|c|}{$\mathrm{T}=288.15 \mathrm{~K}$} \\
\hline 0.13 & -1.95 & 1.05 & -1.65 \\
\hline 0.30 & -2.29 & 3.66 & -1.23 \\
\hline 0.57 & -2.50 & 5.36 & -0.95 \\
\hline 0.80 & -1.98 & 4.61 & -0.65 \\
\hline \multicolumn{4}{|c|}{$\mathrm{T}=293.15 \mathrm{~K}$} \\
\hline 0.13 & -2.09 & 0.97 & -1.81 \\
\hline 0.30 & -2.36 & 3.64 & -1.30 \\
\hline 0.57 & -2.54 & 5.36 & -0.97 \\
\hline 0.80 & -2.02 & 4.61 & -0.66 \\
\hline \multicolumn{4}{|c|}{$\mathrm{T}=298.15 \mathrm{~K}$} \\
\hline 0.13 & -2.24 & 0.89 & -1.97 \\
\hline 0.30 & -2.47 & 3.57 & -1.41 \\
\hline 0.57 & -2.58 & 5.36 & -0.99 \\
\hline 0.80 & -2.05 & 4.61 & -0.67 \\
\hline $\mathrm{T}=303.15$ & & & \\
\hline
\end{tabular}




\begin{tabular}{|c|c|c|c|}
\hline 0.13 & -2.40 & 0.81 & -2.15 \\
\hline 0.30 & -2.56 & 3.55 & -1.48 \\
\hline 0.57 & -2.63 & 5.35 & -1.01 \\
\hline 0.80 & -2.08 & 4.61 & -0.68 \\
\hline $\mathrm{T}=308.15 \mathrm{~K}$ & & & 0.00 \\
\hline 0.13 & -2.61 & 0.70 & -2.40 \\
\hline 0.30 & -2.63 & 3.54 & -1.54 \\
\hline 0.57 & -2.67 & 5.36 & -1.02 \\
\hline 0.80 & -2.11 & 4.62 & -0.69 \\
\hline \multicolumn{4}{|l|}{$\mathrm{T}=313.15 \mathrm{~K}$} \\
\hline 0.12 & -2.84 & 0.60 & -2.65 \\
\hline 0.30 & -2.75 & 3.49 & -1.66 \\
\hline 0.57 & -2.72 & 5.36 & -1.04 \\
\hline 0.80 & -2.14 & 4.62 & -0.70 \\
\hline \multicolumn{4}{|l|}{$\mathrm{T}=318.15 \mathrm{~K}$} \\
\hline 0.12 & -3.10 & 0.45 & -2.95 \\
\hline 0.30 & -2.90 & 3.42 & -1.81 \\
\hline 0.57 & -2.76 & 5.36 & -1.06 \\
\hline 0.80 & -2.18 & 4.61 & -0.71 \\
\hline
\end{tabular}

Table 12 The mixing thermodynamic properties of D-glucosamine 2-sulfate sodium salt in the (water $+n$-propanol) binary mixtures at temperature $T$ and pressure $p=0.1 \mathrm{MPa}$.

\begin{tabular}{cccc}
\hline$\chi_{2}$ & $\Delta$ mix $G / \mathrm{kJ} / \mathrm{mol}$ & $\Delta$ mix $S / \mathrm{J} / \mathrm{K} \cdot \mathrm{mol}$ & $\Delta$ mix $H / \mathrm{kJ} / \mathrm{mol}$ \\
\hline $\mathrm{T}=288.15 \mathrm{~K}$ & & & \\
0.07 & -1.97 & 1.04 & -1.67 \\
0.19 & -2.38 & 3.37 & -1.41 \\
0.42 & -2.94 & 5.08 & -1.48 \\
0.68 & -2.63 & 4.69 & -1.28 \\
$\mathrm{~T}=293.15 \mathrm{~K}$ & & & \\
0.07 & -2.04 & 1.05 & -1.73 \\
0.19 & -2.44 & 3.37 & -1.45 \\
0.42 & -2.99 & 5.09 & -1.50 \\
0.68 & -2.66 & 4.70 & -1.29 \\
$\mathrm{~T}=298.15 \mathrm{~K}$ & & & \\
0.07 & -2.14 & 1.05 & -1.83
\end{tabular}




$\begin{array}{llll}0.19 & -2.52 & 3.37 & -1.52 \\ 0.42 & -3.03 & 5.10 & -1.51 \\ 0.68 & -2.70 & 4.70 & -1.30\end{array}$

$\mathrm{T}=303.15 \mathrm{~K}$

0.07

$-2.33$

0.97

$-2.04$

0.19

$-2.59$

3.37

$-1.57$

0.42

$-3.09$

5.10

$-1.54$

0.68

$-2.74$

4.71

$-1.31$

$\mathrm{T}=308.15 \mathrm{~K}$

0.07

$-2.55$

0.88

$-2.28$

0.19

$-2.75$

3.32

$-1.73$

0.42

$-3.17$

5.09

$-1.60$

0.68

$-2.79$

4.69

$-1.35$

$\mathrm{T}=313.15 \mathrm{~K}$

0.07

$-2.81$

0.80

$-2.56$

0.19

$-2.94$

3.26

$-1.92$

0.42

$-3.26$

5.09

$-1.66$

0.68

$-2.85$

4.68

$-1.38$

$\mathrm{T}=318.15 \mathrm{~K}$

0.07

$-3.14$

0.68

$-2.92$

0.18

$-3.15$

3.12

$-2.16$

0.41

$-3.37$

5.05

$-1.76$

0.68

$-2.92$

4.66

$-1.44$ 